\title{
Time History Analysis of Frame Structure Systems by State-space Representation Method
}

\author{
Barham H. Ali" ${ }^{*}$, Brwa Ahmad Saeed ${ }^{2}$, Twana A. Hussein ${ }^{3}$ \\ ${ }^{1}$ Department of Civil Engineering, Faculty of Engineering, Tishk International University, Erbil, Kurdistan Region, Iraq, ${ }^{2}$ Department of Civil \\ Engineering, Faculty of Engineering, Tishk International University, Erbil, Kurdistan Region, Iraq, ${ }^{3}$ Department of Civil Engineering, Faculty of \\ Engineering, Tishk International University, Erbil, Kurdistan Region, Iraq
}

\author{
${ }^{*}$ Corresponding author: \\ Barham H. Ali, \\ Department of Civil \\ Engineering, Faculty \\ of Engineering, Tishk \\ International University, Erbil, \\ Kurdistan Region, Iraq. \\ E-mail: barham.haydar@ \\ ishik.edu.iq
}

Received: 02 December 2019

Accepted: 05 January 2020

Published: 30 June 2020

DOI

10.25156/pti.v10n1y2020.pp140-147

\section{A B S T R A C T}

This paper develops the state-space representation (SSR) in the field of seismic analysis of the building structures. Dynamic analysis of multi-degree-of-freedom structures involves the solution of second-order linear differential equations which they represent the equation of motion of the structure. In this paper, a SSR was formulated to replace differential equation with two coupled first-order linear differential equations. The objectives of this study are as follows: (i) To implement the SSR as a powerful tool in dynamic analysis of frame structures and (ii) to conduct a linear time history analysis for large structures subjected to ground acceleration and the seismic responses of the building were studied as well. The analysis was based on the assumption that the system is elastic linear time-invariant system and material nonlinearity is not considered. The $1940 \mathrm{El}$-Centro earthquake time history record has been used in the study. There are many effective traditional methods which can be used for carrying out linear dynamic analysis of the structures, however, this paper introduces a state-space model as an alternative approach to perform this analysis. The advantage of this method, it works properly with MATLAB software, gives explicit result for time-invariant systems, applied to multi-input and multioutput control systems, solve the equation of motion for complicated dynamic problems.

Keywords: State-space model; Time history analysis; Frame structures; Dynamic analysis; Linear time-invariant systems

\section{INTRODUCTION}

In modern city, the construction of multiple story buildings has been increased due to increase of populations. Seismic analysis must be operated for structures in earthquake prone zones to ensure satisfactory performance of the building. To study the complete time history response of the building, engineers should carry out seismic analysis which involves seismic excitation load at the structure's base and solution of differential equations. Time history analysis gives the full response of the building during and even after the application of the dynamic loads, unlike response spectrum analysis which only gives the peak seismic response. Time history analysis is conducted to evaluate the seismic performance of a structure under dynamic loading of an excited ground motion (Wilkinson and Hiley, 2006). Time history analysis is a technique used to determine the dynamic response of a structure under the action of any time-dependent loads (SK, M. M., SK, S. M., SK, C. O., and SK, P. O.). Time history analysis is used to determine the seismic response of a structure under dynamic loading of representative earthquake (Wilkinson and Hiley, 2006). Time history analysis is a step-by-step analysis of the dynamic response of a structure to a specified loading that may vary with time (Patil and Kumbhar, 2013). The ordinary differential equations are widely used in many engineering and applied science applications, because most of the physical laws are simply formulated as differential equations. However, the most common use of differential equations is in the study of complex control systems. In the disciplinary of civil engineering, differential equations are formulated in such a way that best describes the vibration of building structures called (equation of motion). The equations of motion are formed in terms of second-order non-homogenous differential equations. Therefore, the solutions of these equations are very complicated and require high computational efforts, for linear time-invariant (LTI) systems with time-dependent loads (Wang, 1998). However, one can get benefit of the solution algorithms developed for the first-order equations (Mendoza Zabala, 1996). Converting the governing differential equations to a set of first-order equations is the standard approach for most disciplines (Mendoza Zabala, 1996). The generalized displacements and velocities of nodal degrees of freedom as global state variables were used for this purpose (Simeonov et al., 2000). 


\section{TIME HISTORY ANALYSIS METHODS}

This study is concerned with computational aspects of the state-space representation (SSR) for frame structural systems with the focuses on the implementation of this model in the structural control problems. Although there are some conventional methods to carry out time history analysis, the direct integration and mode superposition methods are among most popular methods used for the time history analysis.

- The direct integration method solves the second-order differential equation which represents the equation of motion of the structure directly uses numerical step-bystep procedure without transforming the function into other forms, it convergence only when small time steps are used in the analysis which makes the procedure very time consuming and cost effective, therefore, its only good for short duration analysis. The most difficult part of this analysis is the selection of time steps, because big time steps lead to inaccurate results while very small time steps increase the analysis cost

- The mode superposition method uses transform function to decouple the equation of motion into a form with less costly step-by-step solution called modal coordinates although it's very effective and well describe control systems and their individual components. However, the transfer function makes this method not be suitable for multi-inputs multioutputs (MIMO) systems, because transfer function representation makes the system more complex. An example for such a case is seismic analysis of a structure and dampers added to consume vibration energy. Mode superposition method is used to obtain natural vibration frequency and period for each mode as shown in Tables 3 and 4 respectively

- In this paper, an alternative method is introduced to simplify the system without having to use integral transforms. The solution to this problem is SSR. State-space analysis method is suitable for all types of systems; such as single-input single-output (SISO) systems, MIMO systems, linear and non-linear systems, and time varying and time-invariant systems. By converting higher order equations to set of first-order equations and analyzing these first-order differential equations in vector forms, it can be easily account for systems with MIMO, without adding much unnecessary complexity. This state variable representation has some conceptual advantages over the more conventional transfer function representation (Luenberger, 1964). The aforementioned SSR provides the dynamics as a set of coupled first-order differential equations in asset of internal variables which is known as state variables, together with a set of algebraic equations that combine the state variables into physical output variables (Javed et al., 2008). Literature review confirmed that state-space method has both accuracy and short time advantages significantly decrease the cost of the analysis.

The problem studied in this research is described mathematically as a set of input, output, and state variables related by first-order linear differential equations in the state-space model. The characteristic of the structure is assumed to be linear and the non-linearity of structural materials has been ignored. Consequently, the equilibrium is formulated with respect to the deformed geometry of the structure. The state-space model was developed to best satisfy this condition.

\section{ASSUMPTIONS FOR LINEARITY}

- Structural displacements are infinitely small

- No changes in the nature of the boundary conditions during and after the analysis

- Structural materials are elastic

The above three assumptions lead to the expression of the vector of internal forces as Kx. The general finite element formulation of the inertia forces is $M x$ and of the damping forces is $D \dot{x}$, either for linear or non-linear analysis (Bathe, 1982).

\section{RESEARCH APPROACHES}

Studying the dynamic equilibrium analysis of structures is necessary as it considers internal and external forces acting on the building. The below equation is a free vibration equation of motion for undamped multi-degree-offreedom (MDOF) systems (Chopra, 2001). Based on the three assumptions made above, the differential equation is written in such way so that the inertia forces $M \ddot{x}$ together with the dissipative forces $D \dot{x}$ and elasticity forces $(K x)$ are equilibrating the external forces.

$$
M \ddot{x}+D \dot{x}+K x=0
$$

This is a governing second-order differential equation. To describes the behavior of the structural building subjected to ground acceleration without any external dampers added to increase the performance of the building, the above equation changed to;

$$
M \ddot{x}(t)+D \dot{x}(t)+K x(t)=-M \lambda \ddot{x}_{g}(t)
$$

Where, $M$ is the mass matrix, $D$ is the damping matrix that approximates the energy dissipation due to structural 
materials only, $K$ is the stiffness matrix of the structure, $x$, $\dot{\mathrm{X}}$ and $\ddot{x}$ are time varying vectors of floor displacement, velocity, and acceleration, respectively. $\lambda$ is a vector of ones, if there is any external forces or ground acceleration. $\lambda$ is zero, if there is no external force or ground accelerations, and $\ddot{x}_{g}$ is a vector of the acceleration due to selected earthquake. $\ddot{x}_{g}$ is a time-dependent load. The damping matrix is assumed to be proportional to the mass and stiffness matrices. There are many different ways to solve it, mostly are very time consuming or lead to inaccurate solutions, SSR provides a perfect solution.

$$
\ddot{x}(t)=-M^{-1} D \dot{x}(t)-M^{-1} K x(t)-\lambda \ddot{x}_{g}(t)
$$

\section{Inputs, Outputs, and States of the System}

System inputs: The notation $u(t)$ is column vector used to represent the system's input signals. For undamped system subjected to earthquake loads, there is only one input signal which is ground acceleration $\ddot{x}_{g}$, therefore, the force is defined as

$$
\ddot{x}_{g}(t)=u(t)
$$

State: It's a minimal number of sets of first-order differential equations utilized in SSR. Number of sets depends on the order of the differential equation which is used to mathematically describe the behavior of dynamical system. In general, there should be $\mathrm{n}$ state equations for dynamic system with $\mathrm{n}^{\text {th }}$ order differential equation. Then, the vector notations are used to collect together the entire state variables in sets of a state vectors (Rowell, 2002). The concept of the state of a non-linear dynamic system refers to a minimum set of variables, known as state variables that fully describe the system and its response to any given set of inputs (Li and Pileggi, 2003).

As the equation of motion for the multistory building structures is a second-order differential equation; which means that there should be at least two states of the system at initial condition $\left(t=t_{0}\right)$ to completely describe the state of the system at any time during the ground excitation. The state variables for frame structures systems are as follows; the displacements $z_{1}(t)$ and velocities $z_{2}(t)$, and the acceleration is the third state it can be obtained from the other two states. Then, two first-order differential equations should be written to represent the states above $\dot{z}_{1}(t)$ and $\dot{z}_{2}(t)$.

$$
\ddot{x}(t)=-M^{-1} D \dot{x}(t)-M^{-1} K x(t)-\lambda \ddot{x}_{g}(t)
$$

Let, the first state variable be the displacement and the second state variable be velocity

$$
\begin{gathered}
z_{1}(t)=x(t) \text { Displacement } \\
z_{2}(t)=\dot{x}(t) \text { Velocity }
\end{gathered}
$$

Converting the $\mathrm{N}$-order governing differential equations into a set of coupled first-order differential equations, to find $z_{1}$ knowledge of $z_{2}$ is required, on the other hand, to find $z_{2}$ knowledge of $z_{1}$ is required, this system is called coupled system. The SSR can be thought of as a partial reduction of the equation list to a set of simultaneous differential equations rather than to a single higher order differential equation (Javed et al., 2008).

From the definition of velocity, we find that the first differential equation is given by

$$
\begin{aligned}
& \dot{z}_{1}(t)=\dot{x}(t) \\
& \dot{z}_{2}(t)=\mathrm{x}(t)
\end{aligned}
$$

The following are two first-order differential equations replacing the second-order differential equation

$$
\begin{gathered}
\dot{z}_{1}(t)=z_{2}(t) \\
\dot{z}_{2}(t)=-M^{-1} D{z_{2}}_{2}(t)-M^{-1} K z_{1}(t)-\lambda \mu(t)
\end{gathered}
$$

Therefore, the $2^{\text {nd }}$ order differential equation can be written in the matrix form of two $1^{\text {st }}$ order differential equations.

$$
\left|\begin{array}{l}
\dot{z}_{1}(\mathrm{t}) \\
\dot{\mathrm{z}}_{2}(\mathrm{t})
\end{array}\right|=\left|\begin{array}{cc}
\mathrm{I} & 0 \\
-\mathrm{M}^{-1} \mathrm{D} & -\mathrm{M}^{-1} \mathrm{~K}
\end{array}\right|\left|\begin{array}{c}
\mathrm{z}_{2}(\mathrm{t}) \\
\mathrm{z}_{1}(\mathrm{t})
\end{array}\right|+\left|\begin{array}{c}
0 \\
-\lambda
\end{array}\right| \mu(\mathrm{t})
$$

The left side of the state equation is a first-order derivative of the state variables, and the right side is the state variables multiplied by stiffness and mass matrices, and input vector.

Matrix form of SSR for LTI dynamic systems subjected to time-dependent load is:

$$
\begin{gathered}
Z(t)=\left|\begin{array}{l}
z_{1}(t) \\
z_{2}(t)
\end{array}\right| \text { and } \dot{Z}(t)=\left|\begin{array}{c}
\dot{z}_{1}(t) \\
\dot{z}_{2}(t)
\end{array}\right| \\
\left|\begin{array}{l}
\dot{z}_{1}(t) \\
\dot{z}_{2}(t)
\end{array}\right|=\left|\begin{array}{cc}
0 & I \\
-M^{-1} K & -M^{-1} D
\end{array}\right||| \begin{array}{l}
z_{1}(t) \\
z_{2}(t)
\end{array}|+| \begin{array}{c}
0 \\
-\lambda
\end{array} \mid \mu(t)
\end{gathered}
$$

The state vector $Z(t)$ contains enough information to completely summarize the past behavior of the system, and therefore, the future behavior is controlled by a simple first-order differential equation (Luenberger, 1964).

For linear time history analysis, material non-linearity is not considered during the whole analysis process, so the mass, 
stiffness, and damping matrices do not vary with time. Therefore, the system is considered LTI system. If the dynamical system is LTI and has finite dimensional, then the differential equation may be written in matrix form (Hangos et al., 2001). The following is SSR for an LTI system.

$$
\begin{gathered}
\dot{Z}(t)=A Z(t)+B u(t) \text { State Equation } \\
y(t)=C Z(t)+D u(t) \text { Output Equation }
\end{gathered}
$$

System output: The notation $y(t)$ is used to represent the system's output signals. In the case of structural response analysis, there are three different output signals which are displacement $z_{1}(t)$, velocity $z_{2}(t)$, and acceleration $\dot{z}_{2}(t)$

The state-space matrices are as follows:

Matrix A is the system matrix, of the size $(2 n, 2 n)$, represents the effect of current state on the state change. If the state change is not dependent on the current state, this matrix will be a zero.

$$
\mathrm{A}=\left[\begin{array}{cc}
0 & \mathrm{I} \\
-\mathrm{M}^{-1} \mathrm{~K} & -\mathrm{M}^{-1} \mathrm{D}
\end{array}\right]_{2 n^{*} 2 n}
$$

Where, $n$ is number of degree of freedom for the structure.

Matrix $\mathrm{B}$ is the control matrix, of the size $(2 n, m)$. Through the $B$ matrix, the system input affects the state change. If the state change is not dependent on the system input, then $\mathrm{B}$ matrix will be a zero. Where, $\mathrm{m}$ is number of inputs, here the only input is ground acceleration, so $m=1$

$$
\mathrm{B}=\left[\begin{array}{r}
0 \\
-»
\end{array}\right]_{2 n^{*} m}
$$

Matrix $\mathrm{C}$ is the output matrix, of the size $(n, 2 n)$ and determines the relationship between the system state and the system output.

$$
C=\left[\begin{array}{cc}
1 & 0 \\
0 & 1 \\
-M^{-1} K & -M^{-1} D
\end{array}\right]_{3 n \cdot 6 n}
$$

Matrix $D$ is the feed-forward matrix, of the size $(n, 1)$. $\mathrm{D}$ matrix allows the system input directly affect the system output, $D$ matrix is a zero matrix, if the output is displacement or velocity.

$$
D=\left[\begin{array}{c}
0 \\
0 \\
-\lambda
\end{array}\right]_{3 n \cdot 1}
$$

\section{Matrix Form for MIMO State-space System}

$$
\left[\begin{array}{c}
y(t) \\
j(t) \\
y(t)
\end{array}\right]=\left[\begin{array}{cc}
1 & 0 \\
0 & 1 \\
-M^{-1} K & -M^{-1} D
\end{array}\right]|| \begin{aligned}
& z_{1}(t) \\
& z_{2}(t)
\end{aligned} \mid+\left[\begin{array}{c}
0 \\
0 \\
-\lambda
\end{array}\right] \mu(t)
$$

Although, state-space analysis is good for MIMO systems. However, the structure utilized in this paper is uncontrolled by dampers, therefore the only input signal is a ground acceleration which is mean that there is a single input. The outputs of this dynamic system could be any of the following responses displacement, velocity, and acceleration, or all of them.

For more explicit results, a separate output equation was defined for each response to convert the system to SISO system. Matrix forms for $\mathrm{C}$ and $\mathrm{D}$ matrices for each type of output.

Output of the time history analysis can be any of the following acceleration, velocity, and displacement along specific direction for each selected time intervals.

Displacement

Let $y=x$

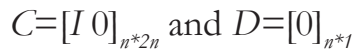

$y(t)=\left[\begin{array}{ll}\mathrm{I} & 0\end{array}\right]\left|\begin{array}{l}Z_{1}(t) \\ Z_{2}(t)\end{array}\right|+[0] \mu(t)$

Velocity

Let $y=\dot{x}$

$C=[0 \text { and } \mathrm{I}]_{n^{*} 2 n}$ and $D=[0]_{n^{* 1}}$

$\dot{y}(t)=\left[\begin{array}{ll}0 & \mathrm{I}\end{array}\right]\left|\begin{array}{l}z_{1}(t) \\ z_{2}(t)\end{array}\right|+[0] \mu(t)$

Acceleration:

Let $y=x$

$C=\left[\begin{array}{ll}-M^{-1} K & -M^{-1} D\end{array}\right]_{n * 2 n}$

and $D=[-\lambda]_{n^{* 1}}$ 


$$
y(t)=\left[\begin{array}{ll}
-M^{-1} K & -M^{-1} D
\end{array}\right]\left|\begin{array}{l}
z_{1}(t) \\
z_{2}(t)
\end{array}\right|+[-\lambda] \mu(t)
$$

\section{MATLAB Code Used to Solve LTI System}

ss command is used to convert dynamic system models to state-space model form this operation is called SSR. ("Create state-space model, convert to state-space model MATLAB ss," n.d.) (available at:https:/ /www.mathworks. $\mathrm{com} / \mathrm{help} / \mathrm{control} / \mathrm{ref} / \mathrm{ss} . \mathrm{html}$ )

$$
\text { sys }=s s(A, B, C, D)
$$

("Simulate Time Response of Dynamic System to Arbitrary Inputs - MATLAB lsim”) [15]

$$
[y, t]=l \operatorname{sim}(\operatorname{sys}, u g, t)
$$

\section{Case Study}

A mathematical model of one way and one bay with five story frame with a story height of $4 \mathrm{~m}$ was designed for the purpose of applying the developed model of SSR, the model is shown in Figure1. The basic concept for this analysis is to idealize the structural model as a soft column rigid beam structure with total story mass lumped at each floor. The analysis was based on the assumption that the system is elastic LTI system and material nonlinearity is not considered. The aim of this case study was to conduct a linear time history analysis and determine the structural response. The 1940 El-Centro earthquake time histories have been used in the study.

The description of mathematical model

- The floor plates were designed as rigid members (floor $\mathrm{I}=\infty$ ) for two purposes

1. Reduce the total number of degrees of freedom from $4^{\circ}$ to $2^{\circ}$

2. Reduce the analysis time.

- Height of the story: $h=4 m$

- Seismic weight of the building has been determined using the modal analysis. The total mass is assumed to be equal at each story and lumped at the center of the story level (Saatcioglu and Humar, 2003) and (Waghmare et al., 2012). Total story mass: $m=80 \mathrm{KN} \cdot \mathrm{s}^{2} / \mathrm{m}$ [Table 1].

- W21×201 American standard section was used for columns which have

$$
\begin{aligned}
& \text { Moment of inertia } I=2210 e-6 \mathrm{~m}^{4} \\
& \text { Modulus of elasticity } E=2 e+8 \mathrm{KN} / \mathrm{m}^{2} \text {. }
\end{aligned}
$$

- The stiffness for each column is calculated independently as follows

$$
K=\text { number of clumns } \times \frac{12 E I_{\text {column }}}{b^{3}}
$$

Then, the stiffness for all columns is combined to determine the global stiffness matrix of the system. system as shown in Table 2.

Here, the system is defined as a continuous time system, in continuous time, the time sampling $d t=t(2)-t(1)$ is used to discretize the continuous model. Likewise, the direct integration method in time history analysis, one should highly consider about the value of the time steps, since it's significantly affect the analysis results and costs so that the time steps must be small enough to obtain accuracy in the solution, but at the same time, it must not be too small to avoid the additional computational costs. Time increments of $0.005 \mathrm{~s}$ used in this study. The choice of sampling period can drastically affect simulation results.

\section{MATLAB Code used for Time Increments}

$\mathrm{t}_{1}=0: 0.02:($ length $($ ug $)-1) * 0.02$

$\mathrm{t}=0: 0.005: \mathrm{t}_{1}(\mathrm{end})$

$[\mathrm{ug}]=$ interp1 $\left(\mathrm{t}_{1}, \mathrm{ug}, \mathrm{t}\right)$;

Full-time history record of El-Centro earthquake was used in this article and the record is shown in Figure 2. The analysis results for displacement, velocity, and acceleration response spectra's due to selected ground motion are plotted in Figures 3-5, respectively. Figures 6-8 illustrate per story max. displacement, max. velocity, and max. acceleration versus story number. Tables 5-7 tabulate the max. displacement, max. velocity, and max. acceleration results obtained from the analysis for each story of MDOF structure, respectively.

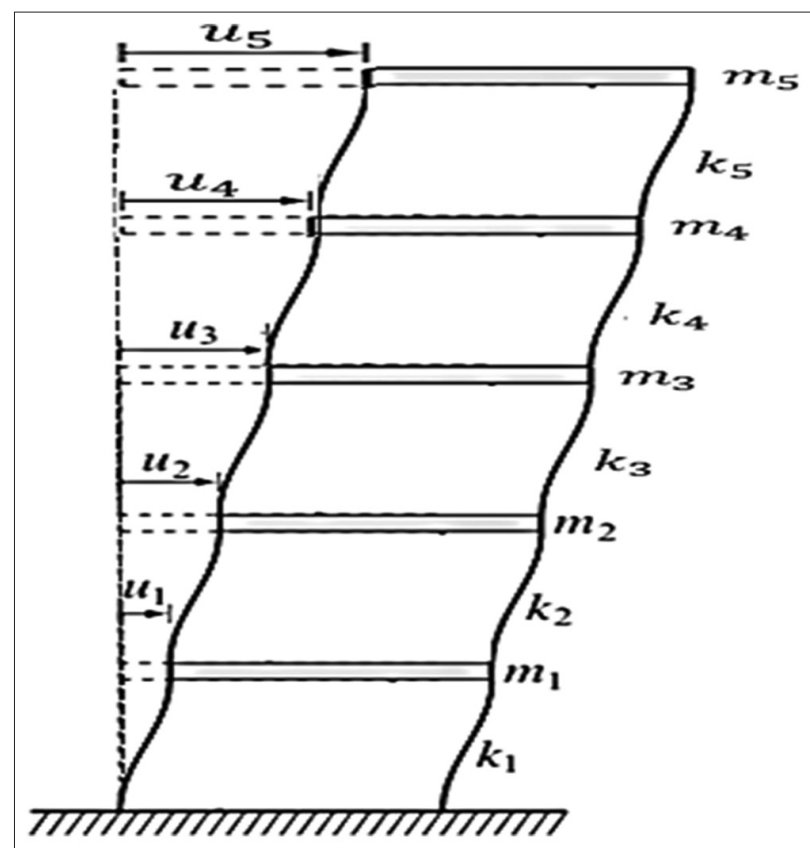

Figure 1: Mathematical model 


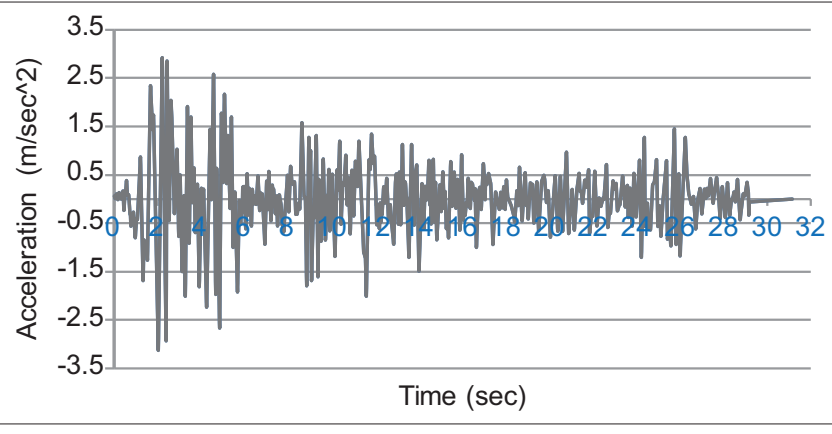

Figure 2: El-Centro ground motion record, 1940

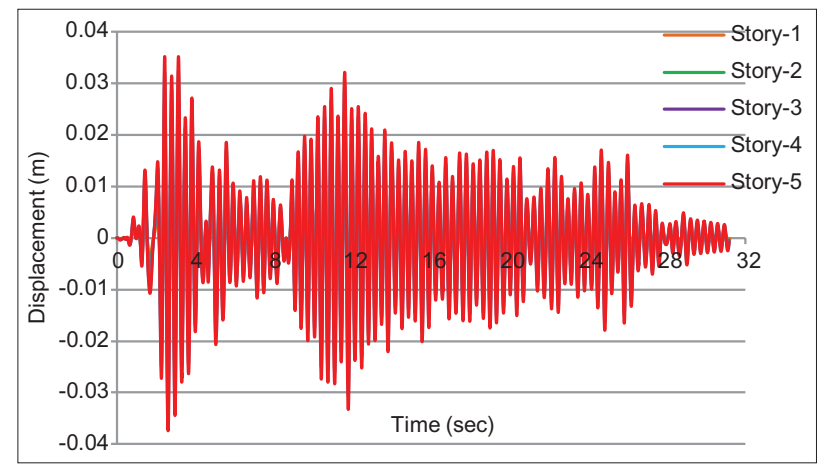

Figure 3: Response spectra displacement at each story

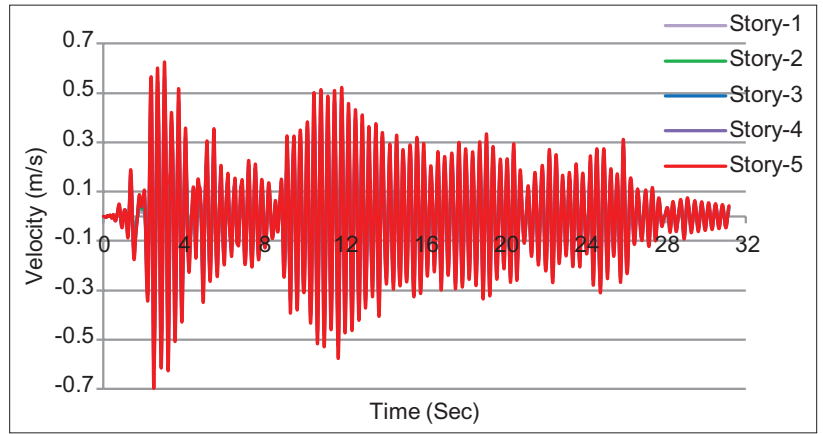

Figure 4: Response spectra velocity at each story

Table 8 tabulates the data of interstory drifts and interstory ratio obtained as the difference between the maximum displacement of two adjacent story's which can be expressed as a percentage of the story height and Figure 9 shows the interstory drift ratio versus story number.

\section{RESULTS}

Maximum displacement response with the peak value of $0.0374 \mathrm{~m}$ occurs at floor number five at $2.61 \mathrm{~s}$, as shown in Figure 3.

Maximum velocity response with the peak value of $0.6973 \mathrm{~m} / \mathrm{s}$ occurs at floor number five at $2.505 \mathrm{~s}$, as shown in Figure 4.

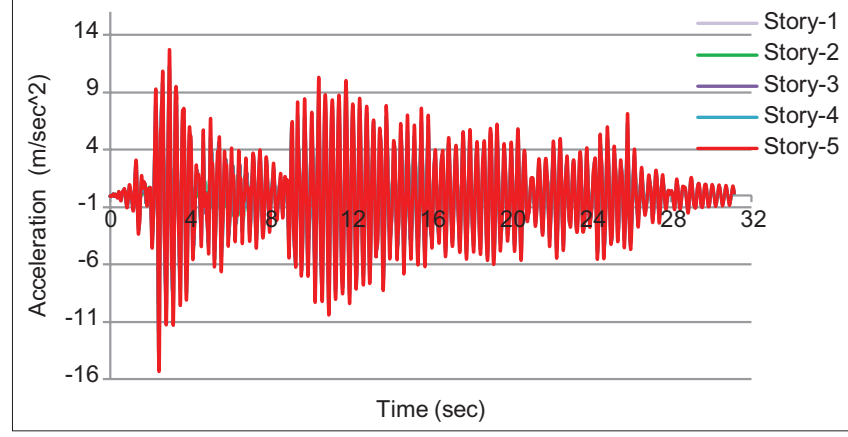

Figure 5: Response spectra acceleration at each story

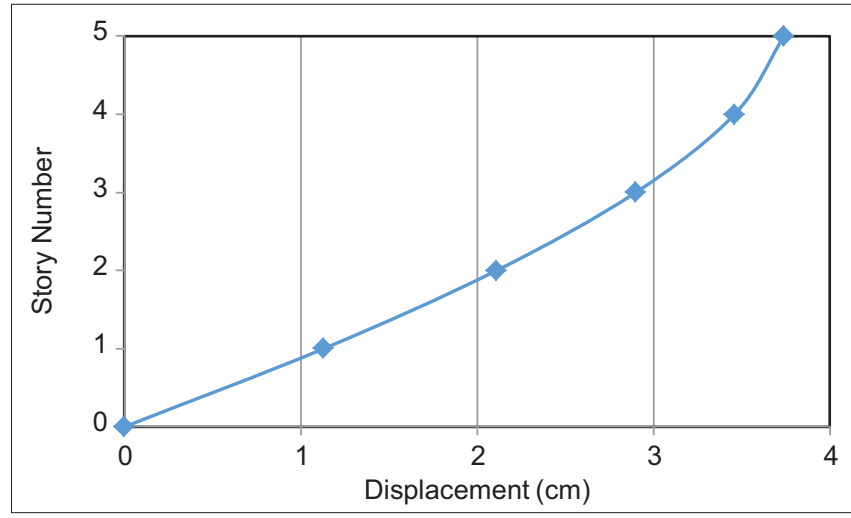

Figure 6: Max. relative displacements

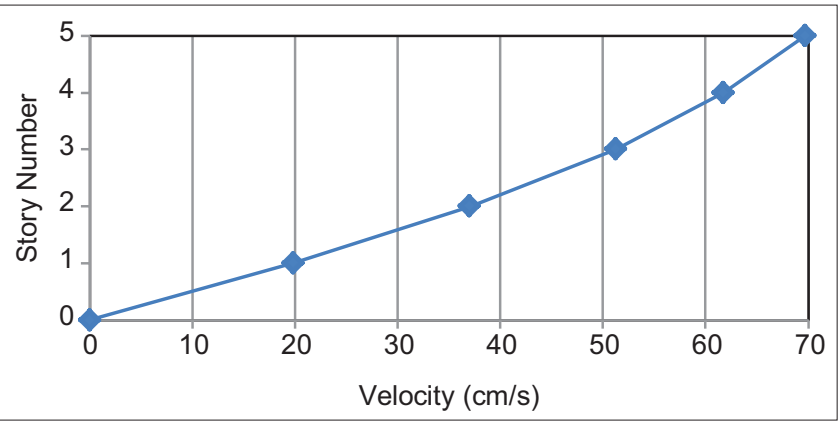

Figure 7: Max. relative velocity

Table 6 shows clearly that the velocity decreases down relatively with the story height. The velocity is greatest at the base and decrease to minimum at story five.

Maximum acceleration response with the peak value of $15.34 \mathrm{~m} / \mathrm{s}^{2}$ occurs at story number five at $2.45 \mathrm{~s}$, as shown in Figure 5.

Figure 5 shows the response of the system in terms of time histories (amplitudes vs. time), when the base of the structure has been shake by seismic waves, it cause the vibration in the structure, this vibration transfer to the whole of the building. The acceleration increases from first floor to the maximum acceleration at fifth floor. 
Table 1: Mass matrix of five story structure $\left(\mathrm{KN} \cdot \mathrm{s}^{2} / \mathrm{m}\right)$

\begin{tabular}{lcccc}
\hline $\mathbf{M}_{1}$ & 0 & 0 & 0 & 0 \\
0 & $M_{2}$ & 0 & 0 & 0 \\
0 & 0 & $M_{3}$ & 0 & 0 \\
0 & 0 & 0 & $M_{4}$ & 0 \\
0 & 0 & 0 & 0 & $M_{5}$ \\
\hline
\end{tabular}

Table 2: Stiffness matrix of five story structure $\left(\mathrm{KN} / \mathrm{m}^{2}\right)$

\begin{tabular}{lcccc}
\hline $\mathrm{k}_{1}+\mathrm{k}_{2}$ & $-\mathrm{k}_{2}$ & 0 & 0 & 0 \\
$-\mathrm{k}_{2}$ & $\mathrm{k}_{2}+\mathrm{k}_{3}$ & $-\mathrm{k}_{3}$ & 0 & 0 \\
0 & $-\mathrm{k}_{3}$ & $\mathrm{k}_{3}+\mathrm{k}_{4}$ & $-\mathrm{k}_{4}$ & 0 \\
0 & 0 & $-\mathrm{k}_{4}$ & $\mathrm{k}_{4}+\mathrm{k}_{5}$ & $-\mathrm{k}_{5}$ \\
0 & 0 & 0 & $-\mathrm{k}_{5}$ & $\mathrm{k}_{5}$ \\
\hline
\end{tabular}

Table 3: Values for omega by mode ( $\mathrm{rad} / \mathrm{s})$

\begin{tabular}{lcccc}
\hline 9.249 & 0 & 0 & 0 & 0 \\
0 & 26.999 & 0 & 0 & 0 \\
0 & 0 & 42.561 & 0 & 0 \\
0 & 0 & 0 & 54.675 & 0 \\
0 & 0 & 0 & 0 & 62.360 \\
\hline
\end{tabular}

Table 4: Values for time period by mode (s)

\begin{tabular}{lcccc}
\hline 0.679 & 0 & 0 & 0 & 0 \\
0 & 0.232 & 0 & 0 & 0 \\
0 & 0 & 0.148 & 0 & 0 \\
0 & 0 & 0 & 0.115 & 0 \\
0 & 0 & 0 & 0 & 0.101 \\
\hline
\end{tabular}

Table 5: Max. displacements at each story

\begin{tabular}{lc} 
Story & Max. displacement $(\mathbf{c m})$ \\
\hline St. 5 & 3.74 \\
St. 4 & 3.46 \\
St. 3 & 2.90 \\
St. 2 & 2.11 \\
St. 1 & 1.13 \\
\hline
\end{tabular}

Table 6: Max. velocity at each story

\begin{tabular}{lcc}
\hline Story & Max. velocity $(\mathbf{c m} / \mathbf{s})$ & Max. velocity ratio (\%) \\
\hline St. 5 & 69.73 & 1.99 \\
St. 4 & 61.77 & 2.635 \\
St. 3 & 51.23 & 3.555 \\
St. 2 & 37.01 & 4.285 \\
St. 1 & 19.87 & 4.968 \\
\hline
\end{tabular}

Table 7: Max. acceleration at each story

\begin{tabular}{lc}
\hline Story & Max. acceleration $(\mathbf{c m})$ \\
\hline St. 5 & 515.22 \\
St. 4 & 944.3 \\
St. 3 & 1191.8 \\
St. 2 & 1391.31 \\
St. 1 & 1534.51 \\
\hline
\end{tabular}

From the analytical result, it has been observed that the mathematical model used in this paper behaved exactly as a real structure. Furthermore, the structural behavior
Table 8: Interstory drifts $(\mathrm{m})$ and interstory ratio

\begin{tabular}{lcc}
\hline Story & Interstory drifts $(\mathrm{cm})$ & Interstory drift ratios $(\%)$ \\
\hline St. 5 & 0.28 & 0.07 \\
St. 4 & 0.56 & 0.14 \\
St. 3 & 0.79 & 0.1975 \\
St. 2 & 0.98 & 0.245 \\
St. 1 & 1.13 & 0.2825 \\
\hline
\end{tabular}

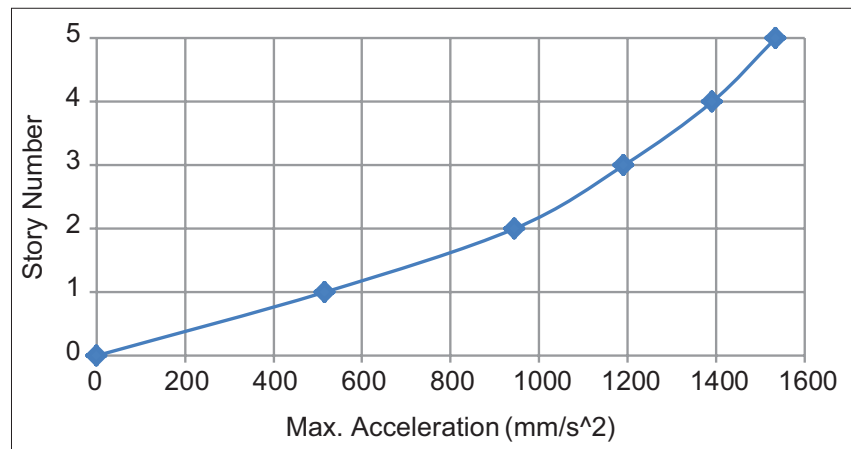

Figure 8: Max. relative acceleration

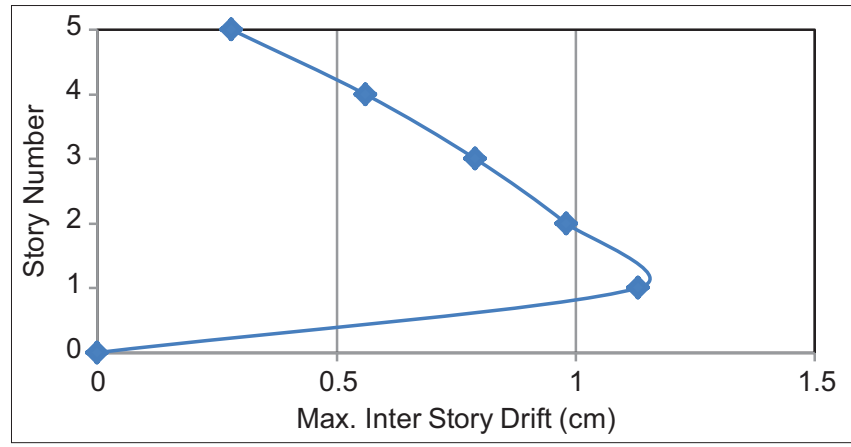

Figure 9: Max. interstory drift ratios versus story numbers

was also compared with the results obtained in Waghmare et al., 2012, and Dyke et al., 1996, and the comparison was accepted. Figures 2 and 5 also showed that the building acceleration was identical with the exact ground acceleration used in the analysis.

\section{CONCLUSION}

In this study, an optimized analysis methodology using SSR has been approached for linear time history analysis. The new mathematical model is implemented to a regular five story one bay one-way steel frame. The objective was to compute the structural response to given ground motion (El-Centro). The research conducted that dynamic analysis with SSR is an excellent way for the analysis of complicated control systems. The following are advantages of this method;

- With state variable one can get full description of a dynamic system at any given instant of time during the ground motion 
- State-space models work excellently with MATLAB, very small time steps could be used as it's not affected by the computational costs

- $\quad$ State-space analysis is applied to LTI and multi-input multi-output systems, so it allows the engineers to get different time response spectra analysis both graphically and analytically in one analysis run.

\section{REFERENCES}

Bathe, K. J. 1982. Finite Element Procedures in Engineering Analysis. Prentice-Hall, United States.

Chopra, A. K. 2001. Dynamics of Structures: Theory and Applications to Earthquake Engineering. Prentice-Hall, United States.

Create State-space Model, Convert to State-space Model-MATLAB ss. n.d. Available from: https://www.mathworks.com/help/control/ ref/ss.html. [Last accessed on 2020 Jan 01].

Dyke, S. J., B. F. Jr. Spencer, M. K. Sain and J. D. Carlson. 1996. Modeling and control of magnetorheological dampers for seismic response reduction. Smart Mater. Struct. 5(5): 565.

Hangos, K. M., R. Lakner and M. Gerzson. 2001. Fuzzy control systems. In: Intelligent Control Systems: An Introduction with Examples. Emerald Group Publishing Limited, United Kingdom. p191-226.

Javed, M., H. Aftab, M. Qasim and M. Sattar. 2008. RLC circuit response and analysis (using state space method). Int. J. Comput. Sci. Netw. Secur. 8(4): 48-54.

Li, P. and L. T. Pileggi. 2003. NORM: Compact model order reduction of weakly nonlinear systems. Paper presented at the
Proceedings of the $40^{\text {th }}$ annual Design Automation Conference, United States.

Luenberger, D. G. 1964. Observing the state of a linear system. IEEE Trans. Mil. Electron. 8(2): 74-80.

Mendoza Zabala, J. L. 1996. State-space Formulation for Structure Dynamics. Massachusetts Institute of Technology, Massachusetts.

Musil, M., M. Sivy, O. Chlebo and O. Prokop. 2017. Seismic Response of Elevated Liquid Storage Tanks. p978-81.

Patil, A. and P. Kumbhar. 2013. Time history analysis of multistoried RCC buildings for different seismic intensities. Int. J. Struct. Civil Eng. Res. 2(3): 194-201.

Rowell, D. 2002. State-Space Representation of LTI Systems. Available from: http://web.mit.edu/2.14/www/Handouts/ StateSpace.pdf. [Last accessed on 2000 Jan 01].

Saatcioglu, M. and J. Humar. 2003. Dynamic analysis of buildings for earthquake-resistant design. Can. J. Civil Eng. 30(2): 338-359.

Simeonov, V. K., M. V. Sivaselvan and A. M. Reinhorn. 2000. Nonlinear analysis of structural frame systems by the state-space approach. Comput. Aided Civil Infrastruct. Eng. 15(2): 76-89.

Simulate Time Response of Dynamic System to Arbitrary InputsMATLAB Lsim. n.d. Available from: https://www.mathworks.com/ help/control/ref/lsim.html. [Last accessed on 2020 Jan 01].

Waghmare, P. B., P. Pajgade and N. Kanhe. 2012. Response spectrum analysis of a shear frame structure by using MATLAB. Int. J. Appl. Sci. Eng. Res. 1(1): 1-10.

Wang, C. Y. 1998. Dynamic Simulation Tool for Seismic Analysis. Massachusetts Institute of Technology, Massachusetts.

Wilkinson, S. and R. Hiley. 2006. A non-linear response history model for the seismic analysis of high rise framed buildings. Comput. Struct. 84(5-6): 318-329. 